\title{
Linking transformational leadership and core self-evaluation to job performance: The mediating role of felt accountability
}

\author{
Chun-Hsi Vivian Chen ${ }^{a}$, Mei-Ling Yuan ${ }^{b *}$, Roger Seifert ${ }^{c}$, Jen-Wei Cheng ${ }^{d}$ \\ ${ }^{a}$ Professor of Business Administration at National Central University, Taiwan \\ ${ }^{\mathrm{b}}$ PhD student of Business Administration at National Central University, Taiwan \\ ${ }^{\mathrm{c}}$ Professor of Industrial Relations at University of Wolverhampton, UK \\ ${ }^{\mathrm{d}}$ Professor of Business Administration at National Taiwan University of Science and \\ Technology, Taiwan
}

\begin{tabular}{ll} 
ARTICLE INFO & ABSTRACT \\
\cline { 2 - 3 } Article history: & $\begin{array}{l}\text { The present study examines the mediating effects } \\
\text { of felt accountability on the relationship of both } \\
\text { transformational leadership as well as core } \\
\text { self-evaluation on task and contextual } \\
\text { performance. SEM with AMOS was used to } \\
\text { analyze the data collected from questionnaires }\end{array}$ \\
JEL classification: & $\begin{array}{l}\text { distributed to } 302 \text { supervisor-employee dyads. The } \\
\text { concept of felt accountability is based on a social }\end{array}$ \\
J23 & $\begin{array}{l}\text { contingency model of accountability, which is } \\
\text { distinct from the feelings of responsibility or }\end{array}$ \\
L25 & obligation in organizational research. Our \\
hypotheses of the mediating roles of felt & accountability were supported by the data, except that \\
Keywords: & the mediating effect of felt accountability between \\
Felt accountability & the relationship of core self-evaluation and \\
Transformational leadership & contextual performance was not supported. We \\
Core self-evaluation & discuss the implications of these results for \\
Job performance & research and practice in organizations.
\end{tabular}

\section{Introduction}

It would require a great deal of research to empirically reexamine the popular claim that accountability is an organizational panacea. We echo what Ferris, Dulebohn, Frink, George-Falvy, Mitchell, and Matthews (2009) claim that, "our understanding of accountability antecedents, processes, and outcomes is woefully deficient" (p. 528). The rationale for this is, a priori, commonly expressed in the saying that, "all we

*Corresponding author at: Business Administration Department, National Central University, Taoyuan County 32001, Taiwan. Tel.: +886 939 656201. E-mail address: yuan6232@ gmail.com. 
need to do is hold the rascals accountable" (cf., Lerner \& Tetlock, 1999, p. 270). Indeed, a major problem-solving oriented social consensus is that accountability is an essential mechanism for social and personal control (Frink \& Ferris, 1998). However, since performance outcomes are stressed by practitioners, the failure to demonstrate a clear connection between accountability and job performance would impede the advocacy of accountability and its implementation in real organizational settings. An important but implicit proposition of accountability research is that the impacts on member behavior derived through accountability mechanisms are essential for improved organizational performance, "yet in practice we increasingly see evidence of accountability lapses" (Frink \& Ferris, 1998, p. 1260). That may demonstrate a lack of research examining the mediating role of felt accountability on job performance (Frink, Hall, Perryman, Ranft, Hochwarter, Ferris, \& Royle, 2008).

In addition, individual performance of an organization is contingent, inter alia, on the interplay of dispositional characteristics of employees and leaders. Core self-evaluation and transformational leadership, therefore, may act as if "conditions of accountability affect employee behavior in such organizational or human resources systems" (Frink \& Ferris, 1998, p. 1260). This contains broad implications for the emergence of felt accountability and various phases of job performance, and can enrich our understanding of their roles in the performance management process.

The purpose of the present research is to investigate the underlying psychological process of employee-perceived accountability in the relationships between transformational leadership and core self-evaluation and job performance. Furthermore, it seeks to fill a gap in the felt-accountability literature and its empirical connection with job performance. We discuss both the theoretical and practical implications associated with our findings, which include transformational leadership, core self-evaluation and job performance theories. We further argue for a process perspective of the mediating role of felt accountability.

\section{Theory and Hypotheses}

\subsection{The Nature and Effect of Felt Accountability}

Accountability is ubiquitous in organizations and social systems, and is conceptualized as "a real or perceived likelihood that the actions, decisions, or behaviors of an individual, group, or organization will be evaluated by some salient audience, and that there exists the potential for the individual, group, or organization to receive either rewards or sanctions based on this expected evaluation" (Hall, Frink, Ferris, Hochwarter, Kacmar, \& Bowen, 2003, p. 33). The perspective of integrating 
accountability with role theories (Frink \& Klimoski, 1998; Frink \& Klimoski, 2004; Frink et al., 2008) suggests that the nature of accountability in social and organizational systems demands some sort of shared norms and rules at some level to guide behavior or elicit conformity. Felt accountability is therefore deemed to be the adhesive that binds social systems together or the mechanism for maintaining systems and structures (Frink et al, 2008). Thus, felt "accountability is seen as leading to internal pressure to comply" (Ferris, Dulebohn, Frink, George-Falvy, Mitchell, Matthew, 2009, p. 519).

It is worth noting that in contrast with the traditional superior-subordinate relationships or 'vertical' form, other accountability mechanisms are 'horizontal' as existing in the relationships between peers, partners, clients, and independent bodies (Schillemans, 2010). Thus, felt accountability is induced by multiple sources. For example, employees are expected to be accountable to their superiors, colleagues, clients and other stakeholders (Hall, Bowen, Ferris, Royle, \& Fitzgibbons, 2007). Consequently, under the so-called 'web of accountability' (Frink \& Klimoski, 1998) the joint impact of multiple mechanisms may create 'redundant accountability' (Schillemans, 2010).

Instead of examining each of the multiple sources and identifying their individual effects through a multi-level or a meso-level perspective among the redundant accountability, Hall et al. (2007) suggested that accountability can be thought of as a subjective representation of the context. Nevertheless, felt accountability research integrates the impact of intra-psychic processes (Lerner \& Tetlock, 2003) into the conceptual framework to enhance the linkages of individual behavior with the larger organizational and social institutional context.

Specifically, the concept of felt accountability is based on the social contingency model of accountability (Tetlock, 1985, 1992), which is distinct from the feeling of responsibility or obligation in organizational research (Frink \& Ferris, 1998; Hall et al., 2007; Frink et al., 2008). Perceived accountability is subjective and internal in essence. Felt accountability of an individual is partly affected by his/her perceptions and experiences of external accountability contexts (Hochwarter, Perrewe, Hall, \& Ferris, 2005). In this vein, the present study adopts the following definition: felt accountability refers to "an implicit or explicit expectation that one's decisions or actions will be deemed important or noteworthy, and will be subject to evaluation by salient others with the belief that there exists the potential for one to receive either rewards or sanctions" (Hochwarter et al, 2005, p. 518). That is, the person is aware of the need to meet some acceptable standard of behavior and their consequences if they are or are not successful. 


\subsection{Felt Accountability and Job Performance}

Job performance is commonly asserted as the most important outcome for facilitating organizations to predict and control member behavior. To hold people accountable or answerable for their job performance is a basic element in organizational systems (Ferris et al., 2009). Therefore, as Frink et al. (2008) emphasized, "people would have no interest in accountability were it not associated with performance outcomes" (p. 219). Research has shown that organizational cues influence individuals' accountability perceptions, and the effect of felt accountability depends on the decision maker's knowledge of the views of the audience (e.g., Lerner $\&$ Tetlock, 1999). If the views of the audience are known and conformity is likely, then decision makers will act in accordance with these views. Thus, the resulting perception of accountability will be an important determinant of subsequent performance. Additionally, if the organizational function of accountability mechanisms is to make the behavior of the 'focal person' or subordinates more predictable and controllable to achieve organization goals, then it can be expected that the perceived accountability will effect job performance.

Organization research gauges an individual's performance in terms of his/her job performance behaviors (Carter, Armenakis, Field, \& Mossholder, 2013). These are usually separated into task performance (i.e., performance of duties that formally recognized as part of the job) and contextual performance (i.e., performance of extra-role behaviors that is voluntarily done for increasing organizational effectiveness, such as organizational citizenship behavior) (Royle, Hall, Hochwarter, Perrewé, \& Ferris, 2005). Erdogan, Sparrowe, Liden, and Dunegan (2004) suggested that the outcomes of felt accountability could include task and/or contextual behaviors, and they proposed to identify the conditions under which individuals perceive differences in felt accountability for task and contextual behaviors.

\subsection{Transformational Leadership, Felt Accountability, and Job Performance}

It is axiomatic that leadership is critical to the success of any organization. Transformational leadership is recognized as an effective leadership form to facilitate members to cope with the continuous challenges organizations may face (Carter et al, 2013). In terms of felt accountability, the 'focal person' experiences of external events as objective antecedents will evoke the feeling of accountability and result in a series of self-generated influences on the personal determinants of judgment and action (Frink et al., 2008). Thus, transformational leadership can be an important environment antecedent within organizations requiring further exploration for felt accountability research. 
Unlike other types of leadership, 'transformational' leadership is distinguished by focusing on the development of followers. This functions through the process of contingent reinforcement to account for who attempts, who is successful, and who is effective as a leader (Bass, 1995). Theoretically, transformational leaders engage in inspirational activities to energize followers by enhancing their psychological empowerment and self-efficacy, providing them with higher aspirations and identities, and encouraging them to take on more responsibility for work outcomes (Bartram \& Casimir, 2007; Aryee, Walumbwa, Zhou, \& Hartnell, 2012). Khanin (2007) suggested that transformational leaders can increase follower job performance by utilizing motivational tools, such as idealized influence/charisma, inspirational motivation, intellectual stimulation, and individual consideration, to induce higher-order changes that go beyond the expectations of subordinates themselves.

With regard to these social influence processes, for example, transformational leaders help their followers to enhance their social identification and self-concepts. The followers are encouraged to internalize and emulate their leader's values, beliefs and behavior. These kind of interactions, over time, will in turn strengthen the leader-follower ties, including mutual obligation, respect, trust, and interpersonal support (Carter et al., 2013). Thus, through at least being accountable to their leaders as well as to their own jobs, the level of the followers' perceived accountability can be increased. Therefore, transformational leadership is positively related to employees' felt accountability.

Furthermore, these kind of interactions may also make the followers prioritize a larger collective cause over individual interests (Wang, Law, Hackett, Wang, \& Chen, 2005). Followers' awareness and concerns about their evaluation of salient others and their contribution to the workplace goals can be increasingly evoked, and encourage them to work harder. Previous studies have found that transformational leadership is positively related to followers' task performance and contextual performance across most conditions (e.g., Dvir, Eden, Avolio, \& Shamir, 2002; Wang et al., 2005; Wang, Oh, Courtright, \& Colbert, 2011).

Transformational leadership and felt accountability are two different organizational devices to manipulate effects on individuals' behavior based on motivation and/or the impact of intra-psychic processes (cf., Lerner \& Tetlock, 2003). Both constructs can be depicted as targeting behavior changes by means of an inner motivational process being aroused to pursue some sort of outcomes, including job performance (i.e., task performance and contextual performance). The social cognitive model of triadic reciprocal causation (Bandura, 1989) thereby suggests that external environment, cognitive and other personal factors, and behavior interact and influence each other bi-directionally (Wood \& Bandura, 1989, p. 362). Accordingly, 
by taking the primary causal sequence into consideration, this study adopts a mediating model with transformational leadership as the antecedents and job performance as the outcomes of felt accountability (cf., Frink et al, 2008). This study proposes:

Hypothesis 1a: Employees' felt accountability mediates the relationship between transformational leadership and task performance.

Hypothesis 1b: Employees' felt accountability mediates the relationship between transformational leadership and contextual performance.

\subsection{Core Self-evaluation, Felt Accountability, and Job Performance}

Felt accountability, as "the social psychological link between individual decision makers on the one hand and social system on the other" (Lerner \& Tetlock, 1994, p. 2), can be best viewed as a state of mind (Hochwarter, Ferris, Gavin, Perrewé, Hall, \& Frink, 2007). It motivates employees to seek the approval and respect of those to whom they are accountable. Prior studies have found that personality traits play roles in perceived accountability research (Frink \& Ferris, 1998; Mero, Guidice, \& Anna, 2006). Other studies, such as Laird, Perryman, Hochwarter, Ferris, and Zinko (2009) and Hall and Ferris (2010) took negative affect and positive affect as control variables in their analyses of the relationships between perceived accountability, strain, and extra-role behavior. However, these perceived accountability studies merely provided small fragments on the various aspects of personality traits.

Core self-evaluation (CSE; Judge, Locke, \& Durham, 1997) is a dispositional profile that reflects who the individual is and how individuals perceive themselves. Core self-evaluation research utilizes the approach/avoidance frameworks (Elliot \& Thrash, 2002) as its theoretical foundation. It posits that personality traits can be characterized in terms of sensitivity to positive or negative information. People, then, can be categorized into approach (positive) and avoidance (negative) temperaments by which the high-CSE individuals are conceptualized as sensitive to positive stimuli and insensitive to negative stimuli, and vice versa (Chang, Ferris, Johnson, Rosen, \& Tan, 2012).

Specifically, the construct is composed of four CSE traits: self-esteem, generalized self-efficacy, emotional stability, and locus of control. Several studies of Judge and his colleagues confirmed the relationship between CSE and job performance (Erez \& Judge, 2001; Judge \& Bono, 2001; Judge, Erez, Bono, \& Thoresen, 2003; Bono \& Judge, 2003). For example, Bono and Judge (2003) found that the four traits and the CSE construct are related to I/O psychology's two central criteria: job satisfaction and job performance. They suggested further that CSE can 
serve the work of traits evaluation by focusing on the lens through which people view themselves and their world.

Given that CSE is a valid construct for assessing self traits, recently some meta-analytic research has confirmed that CSE is related to individual job performance behaviors. Ones, Dilchert, Viswesvaran, and Judge (2007) suggested that self-reported personality measures were useful in explaining and predicting job satisfaction and other organizational behaviors. Their meta-analysis results revealed that CSE was a useful predictor of performance compared with the Big Five, even when the effect of the entire set of Big Five traits was controlled (Ones et al., 2007). Chang et al. (2012) found in their meta-analysis that CSE was positively related to task performance and organizational citizenship behavior. Based on these prior findings, this study proposes that CSE is positively related to employees' task performance and contextual performance.

Furthermore, Cheng et al. (2012) noted that CSE within an approach/avoidance framework could generate directions for further research on the possible linkages between CSE and decision making. Bono and Judge (2003) suggested that future research could explore what additional psychological or behavioral processes possibly linked CSE to job performance. Such proposed processes include that, for example, the pressure from others or internal feelings of guilt or shame may affect the individual goal-setting and that is more likely to lead greater effort and volitional strength. Besides, individuals with higher CSE are more protective of their reputation and better manage their individual impressions. The meta-analysis of Kammeyer-Mueller, Judge, and Scott (2009) found that positive CSE individuals experience fewer stressors and less strain than individuals with negative CSE, and individuals high in CSE practice less avoidance coping, less emotion-focused coping, and more problem-solving coping than individuals with low CSE. Positive CSE and high in CSE can exert influence on the members' sensitivities of organizational accountability cues. That would arouse a series of self-generated influences on the decision making of coping strategy, accompanied with enhanced perceived accountability, and in turn increasing an individual job performance. Royle et al. (2008) found a mediating effect of informal accountability for others on the relationship between self-regulation and organizational citizenship behaviors. Judge and Kammeyer-Mueller (2011) in their review study have hypothesized a mediating model that higher CSE leads to setting more ambitious goals, which in turn relate to higher levels of performance. Therefore, this study proposes:

Hypothesis 2a: Employees' felt accountability mediates the relationship between core self-evaluation and task performance.

Hypothesis 2b: Employees' felt accountability mediates the relationship between 
core self-evaluation and contextual performance.

\section{Methods}

\subsection{Procedures}

Data for this study were obtained from organizations located in Taiwan. The surveyed organizations were based in six different industry and service sectors. For the purpose of controlling the same-source effect, this study utilized a dyadic questionnaire design by which data were collected from subordinates and supervisors in a typical dyadic relationship. The first subordinate questionnaire was designed as the tool for collecting data on subordinate felt accountability, transformational leadership, and core self-evaluation. As a supplement to the first questionnaire, the second, supervisor questionnaire was independently designed both in form and survey administration for collecting data on subordinate job performance.

The data collection process was handled in two phases. First, the managers, who the authors knew, were contacted to help in the distribution of subordinate questionnaires to the middle level supervisors of their companies. Each supervisor was requested to assign no more than five direct subordinates to fill out the questionnaire and sealed it in an envelope which was then handed back to the supervisor. When the subordinates handed over the sealed envelopes to their supervisor, the supervisors were asked to record both the name and a sequential number (written on the envelope by the supervisors) of each subordinate. In the second phase, the supervisor questionnaires were distributed by the managers to the supervisors to assess the job performance of each of their subordinates following the sequential numbers that they had previously recorded.

\subsection{Participants}

A total of 685 subordinate questionnaires were distributed in this survey. We received 302 useable subordinate questionnaires giving a net response rate of $44 \%$. The missing value questionnaires included the questionnaires with incomplete answers, unidentified dyadic relationships, and from incorrectly identified respondents. The demographic characteristics of the subordinates were as follows: female $51.3 \%$ and male $48.7 \%$; married $54.6 \%$ and single $45.4 \%$; in formal education, master's level and above $20.6 \%$, bachelor level 52.6\%, college level and below $26.8 \%$; in sector, traditional manufacturing $11.6 \%$, hi-tech manufacturing $38.4 \%$, public utilities $25.2 \%$, wholesale and retail $5.6 \%$, transportation, storage and communication $8.6 \%$, and finance and insurance $21.9 \%$. 


\subsection{Measures}

Two anonymous, self-administered questionnaires were employed for data collection of this present study. All the perceptions, dispositions, and attitudes in the subordinate and the supervisor questionnaire, including felt accountability, transformational leadership, core self-evaluation, and job performance, were measured with a five-point Likert scale ranging from 1 (strongly disagree) to 5 (strongly agree). The original English items of each scale used in this study were carefully translated into Chinese by the authors and revised by other local scholars in the field of organizational behavior and senior HR managers in business organizations.

Felt Accountability. The subordinate's felt accountability level was measured by the eight-item scale developed by Hochwarter et al. (2005, p. 523) (e.g. "I am held very accountable for my actions at work").

Transformational Leadership. The twenty-item transformational leadership scale developed by Bass and Avolio (1997) was used for assessing the level of transformational leadership perceived by the subordinates (e.g. "Has a clear understanding of where we are going").

Core Self-Evaluation. This study used the twelve-item Core Self-Evaluations Scale, developed by Judge et al. (2003, p. 315), for measuring the respondents' personality traits (e.g. "I am confident I get the success I deserve in life").

Job Performance. This study used two different measures to assess the sample subordinates' job performance by their supervisors. First, seven items of task performance developed by Williams and Anderson (1991, p. 606) were adopted (e.g. "Adequately completes assigned duties"). The second measure used for assessing the subordinates' contextual performance developed by Motowidlo and Van-Scotter (1994, p. 477) included sixteen items (e.g. "comply with instructions even when supervisors are not present").

\subsection{Analytical strategy}

Structural equation modeling (SEM) with AMOS 17.0 was used to test the hypothesized model. According to Jöreskog and Sörbom (1989) SEM provides a maximum-likelihood estimation of the entire system in a hypothesized model, and enables the assessment of variables with the data. Thus, this study adopted Anderson and Gerbing's (1988) two-step strategy to test the hypothesized model. First, the measurement model was confirmed using confirmatory factor analysis (CFA), and 
then we performed SEM analysis to measure the fit and path coefficients of the hypothesized model. Furthermore, we employed bootstrapping analyses (MacKinnon, Lockwood, Hoffman, West, \& Sheets, 2002; Preacher \& Hayes, 2008) to estimate the mediating and/or indirect effects. Bootstrapping procedures generate an empirical approximation of the sampling distribution that is used to construct confidence intervals (CIs) for indirect effects (Preacher \& Hayes, 2008).

\section{Data Analysis and Results}

\subsection{Confirmatory Factor Analysis}

Confirmatory Factor Analysis (CFA) is also called "the measurement model". When conducting SEM, researchers often first evaluate the measurement model (whether the measured variables accurately reflect the desired constructs or factors) before assessing the structural model (Jackson, Gillaspy, Purc-Stephenson Jr., 2009). As noted by Thompson (2004), "It makes little sense to relate constructs within an SEM model if the factors specified as part of the model are not worthy of further attention" (p. 110).

In many cases, problems with SEM models are due to measurement model issues that can be identified with CFA (Brown, 2006). CFA is an important analytic tool in its own right (Brown, 2006). Kenny (2006) even asserted that "the social and behavioral sciences have learned much more from CFA than from SEM" (p. ix). Thus, we argue that how CFA studies are reported warrants examination separate from SEM studies in general. Of particular importance is the degree to which CFA studies provide sufficient detail about model specification and evaluation to instill confidence in the results. Therefore, we first conducted analysis to understand the quality of the measurement models, then analyzed the structural models.

In this study, the SEM comprised five main dimensions: (a) transformational leadership (TL, item L1-L20, subordinates' evaluation); (b) core self-evaluation (CSE, item S1-S12, subordinates' evaluation); (c) felt accountability (FA, item A1-A8, subordinates' evaluation); (d) task performance (TP, item P1-P7, supervisor's evaluation); and (e) contextual performance (CP, item P8-P23, supervisor's evaluation).

For each dimension, we tested the CFA model goodness of fit, factor loadings, squared multiple correlations (SMC), composite reliability (CR), convergent validity, and inter-dimensional discriminant validity. In the process of CFA analysis, factor loadings lower than 0.45 were removed according to Hooper, Coughlan, and Mullen (2008), Bentler and Wu (1993), and Jöreskog and Sörbom (1989). In accordance with the suggestions made by Kenny (1979) and Hair, Black, Babin, and Anderson (2009), 
at least three items were retained in each dimension for subsequent analysis.

In the case of transformational leadership (TL), this second-order dimension was composed of five dimensions (i.e., idealized attributes [ATTR], idealized behaviors $[\mathrm{BEH}]$, inspirational motivation [MOT], intellectual stimulation [STIM], and individualized consideration [CONSID]). The Cronbach's $\alpha$ of the five sub-dimensions ranged from .83 to .91 , which was higher than the recommended value of .7 (Hair et al., 2009). Therefore, item parcel processing was conducted to attain model simplification. This procedure involved adopting the combining of the items of each dimensions as new variables, representing their original dimension.

In addition to simplifying the model, item parcels can advance the data closer to normalization, reduce the likelihood of correlations between residuals, increase the likelihood of residual independence, and increase the model's goodness of fit (Kline, 2011). Therefore, TL was used as a first-order dimension comprising five items, similar to the other four dimensions. During CFA analysis, factor loadings smaller than .6 were removed, and composite reliability (CR) and average variance extracted (AVE) were calculated. Fornell and Larcker (1981) asserted that a dimension with a CR larger than .7 and an AVE larger than .5 would possess acceptable reliability and convergent validity. Our results are shown in Table 1. Except for the reference indicators that were set to 1 , all non-standardized factor loadings reached the level of significance, and all standardized factor loadings exceeded .6. The SMCs exceeded or approached .5, the CRs all exceeded .7, and AVE exceeded .5 in all instances. Thus, the measurement dimensions of this study possessed favorable convergent validity. 
Table 1. Factor loadings and convergent validity

\begin{tabular}{|c|c|c|c|c|c|c|c|c|c|}
\hline & & Unstd. & S.E. & t-value & $\mathrm{P}$ & Std. & SMC & $\mathrm{CR}$ & AVE \\
\hline \multirow[t]{5}{*}{$\mathrm{TL}$} & ATTR & 1 & & & & 0.904 & 0.817 & 0.942 & 0.764 \\
\hline & $\mathrm{BEH}$ & 0.928 & 0.037 & 24.836 & $* * *$ & 0.908 & 0.824 & & \\
\hline & MOT & 0.974 & 0.043 & 22.816 & $* * *$ & 0.876 & 0.767 & & \\
\hline & STIM & 0.867 & 0.037 & 23.221 & $* * *$ & 0.883 & 0.780 & & \\
\hline & CONSID & 0.879 & 0.047 & 18.650 & $* * *$ & 0.796 & 0.634 & & \\
\hline \multirow[t]{5}{*}{$\mathrm{CSE}$} & S1 & 1 & & & & 0.715 & 0.511 & 0.799 & 0.444 \\
\hline & S5 & 0.921 & 0.095 & 9.694 & $* * *$ & 0.663 & 0.440 & & \\
\hline & S7 & 0.904 & 0.098 & 9.229 & $* * *$ & 0.625 & 0.391 & & \\
\hline & S9 & 1.175 & 0.115 & 10.232 & $* * *$ & 0.713 & 0.508 & & \\
\hline & $\mathrm{S} 11$ & 0.831 & 0.092 & 9.039 & $* * *$ & 0.610 & 0.372 & & \\
\hline \multirow[t]{3}{*}{ FA } & A5 & 1 & & & & 0.620 & 0.384 & 0.746 & 0.500 \\
\hline & A6 & 1.384 & 0.175 & 7.896 & $* * *$ & 0.832 & 0.692 & & \\
\hline & A7 & 0.944 & 0.112 & 8.390 & $* * *$ & 0.650 & 0.423 & & \\
\hline \multirow[t]{4}{*}{ TP } & P1 & 1 & & & & 0.739 & 0.546 & 0.881 & 0.651 \\
\hline & P3 & 1.281 & 0.092 & 13.986 & $* * *$ & 0.831 & 0.691 & & \\
\hline & P4 & 1.342 & 0.092 & 14.606 & $* * *$ & 0.878 & 0.771 & & \\
\hline & P5 & 1.219 & 0.094 & 12.997 & $* * *$ & 0.771 & 0.594 & & \\
\hline \multirow[t]{5}{*}{$\mathrm{CP}$} & P10 & 1 & & & & 0.728 & 0.530 & 0.848 & 0.529 \\
\hline & P11 & 0.960 & 0.078 & 12.279 & $* * *$ & 0.778 & 0.605 & & \\
\hline & P17 & 0.910 & 0.081 & 11.262 & $* * *$ & 0.707 & 0.500 & & \\
\hline & P21 & 1.024 & 0.082 & 12.452 & $* * *$ & 0.792 & 0.627 & & \\
\hline & P16 & 0.839 & 0.085 & 9.920 & $* * *$ & 0.620 & 0.384 & & \\
\hline
\end{tabular}

Note:

(1) $* * p<.01 ; * * p<.001$ (two-tailed); $\mathrm{N}=302$.

(2) $\mathrm{TL}=$ Transformational leadership, $\mathrm{CSE}=$ Core self-evaluation, $\mathrm{FA}=$ Felt accountability, $\mathrm{TP}=$ Task performance, and $\mathrm{CP}=$ Contextual performance.

(3) TL was composed of five dimensions, namely idealized attributes (ATTR; L5, L9, L11, L13), idealized behaviors (BEH; L2, L7, L12, L19), inspirational motivation (MOT; L4, L6, L14, L20), intellectual stimulation (STIM; L1, L3, L16, L18), and individualized consideration (CONSID; L8, L10, L15, L17).

Fornell and Larcker (1981) proposed that when a model possesses discriminant validity, the convergent validity (i.e., AVE) should exceed the shared variance between dimensions. This study compared the AVE square root with Pearson's correlations between dimensions. As Table 2 shows, the AVE square roots exceeded Pearson's correlation values for each dimension, indicating that favorable discriminant validity existed between the dimensions. 
Table 2. Discriminate validity

\begin{tabular}{lcccccc}
\hline & AVE & CP & TP & FA & CSE & TL \\
\hline CP & 0.529 & $\mathbf{0 . 7 2 7}$ & & & & \\
TP & 0.651 & 0.775 & $\mathbf{0 . 8 0 7}$ & & & \\
FA & 0.500 & 0.187 & 0.182 & $\mathbf{0 . 7 0 7}$ & & \\
CSE & 0.444 & 0.117 & 0.084 & 0.299 & $\mathbf{0 . 6 6 6}$ & \\
TL & 0.764 & 0.159 & 0.092 & 0.283 & 0.421 & $\mathbf{0 . 8 7 4}$ \\
\hline
\end{tabular}

\subsection{Structural Models}

In SEM, to evaluate the goodness of fit between the model and sample data based on multiple aspects, a series of empirical indicators were developed (e.g., Tucker-Lewis Index [TLI], incremental fit index [IFI], comparative fit index [CFI], normed chi square $\left[\chi^{2} / \mathrm{df}\right]$, goodness-of-fit index [GFI], adjusted goodness-of-fit index [AGFI], root mean square error of approximation [RMSEA], and standardized root mean square residual [SRMR]). For example, TLI, IFI, CFI, GFI, and AGFI are used to indicate the level of similarity between the model and sample. The value of 1 indicates complete similarity and a value of more than .9 is generally recommended. As for another set of indicators such as RMSEA and SRMR, which indicate the level of divergence between the model and sample, 0 indicates complete divergence and a value below .08 is generally acceptable.

Our analysis results of structural model's goodness of fit are as shown in Table 3. Most of the goodness of fit indicators for the original model exhibited favorable values. The chi-square was 364.022, the normed chi-square was 1.892 (less than the recommended ratio of 3), GFI was .903 (higher than .9), AGFI was .876 (although lower than the recommended value of .9, the result was within an acceptable range), and RMSEA was .052 (less than the recommended value of .08). SRMR was .049 (less than the recommended value of .08), CFI was .954 (exceeding the recommended value of .9), and IFI was .954 (exceeding the recommended value of .9). Overall, the model's goodness of fit satisfied the established standards, demonstrating favorable goodness of fit between the model and sample. 
Table 3. Goodness of fit indicators for the research model

\begin{tabular}{lccc}
\hline \multicolumn{1}{c}{ Fit indices } & Reference value & Model value & $\begin{array}{c}\text { Overall } \\
\text { model fit }\end{array}$ \\
\hline ML $\left(\chi^{2}\right)$ & The smaller the better & 364.022 & - \\
df (Degrees of Freedom) & The bigger the better & 199 & - \\
$\chi^{2} /$ df (Normed Chi-sqrire) & $1<\chi^{2} /$ df $<3$ & 1.829 & Yes \\
GFI & $>0.9$ & 0.903 & Yes \\
AGFI & $>0.9$ & 0.876 & Yes \\
RMSEA & $<0.08$ & 0.052 & Yes \\
SRMR & $<0.08$ & 0.049 & Yes \\
TLI (NNFI) & $>0.9$ & 0.946 & Yes \\
CFI & $>0.9$ & 0.954 & Yes \\
IFI & $>0.9$ & 0.954 & Yes \\
Hoelter's N $(\mathrm{CN})$ & $>200$ & 193 & Yes \\
\hline
\end{tabular}

After an acceptable goodness of fit was obtained for the model, the regression path coefficient results and significance levels were presented in Figure 1. The model included three significant influence paths, namely TL to FA, CSE to FA, and FA to TP. The remaining paths did not reach the significance level of 95\%, as shown in Table 4. 


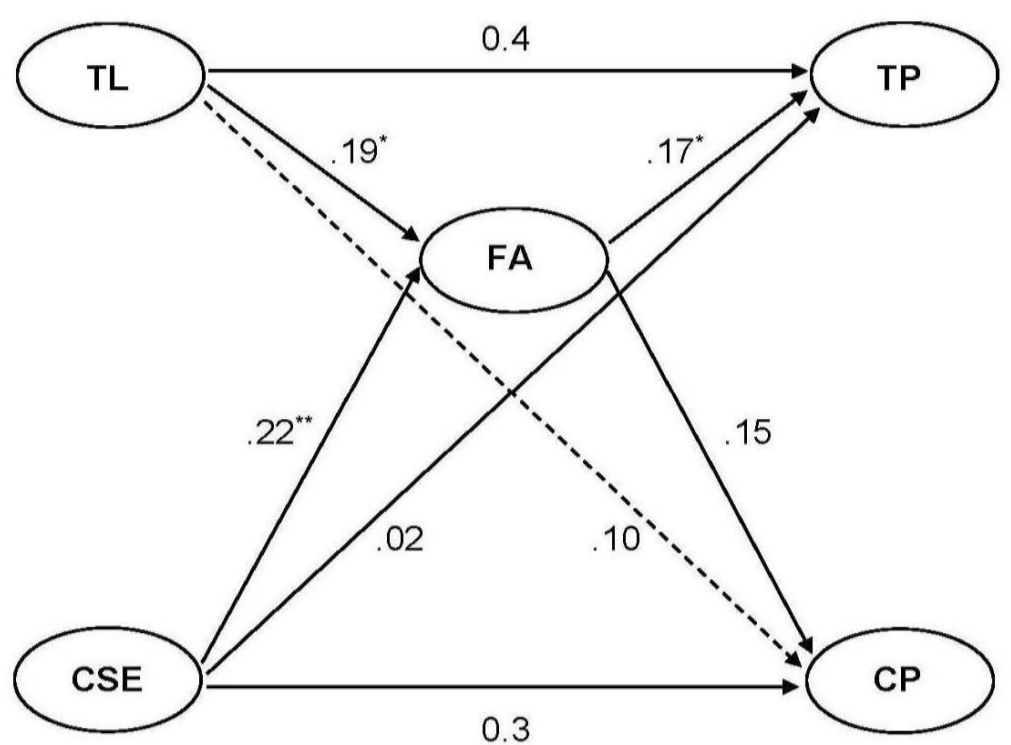

Note: $(1) * \mathrm{p}<.05, * * \mathrm{p}<.01$ (two-tailed); $\mathrm{N}=302$

(2) $\chi^{2}=364.022, \mathrm{df}=199, \chi^{2} / \mathrm{df}=1.829, \mathrm{CFI}=.954$, $\mathrm{IFI}=.954, \mathrm{TLI}=.946$, and $\mathrm{SRMR}=.052$

Figure 1. Structural equation modeling of the hypothesized model

Table 4. Standardized regression coefficient analysis of the model

\begin{tabular}{llllllll}
\hline & & & Unstd. & S.E. & t-value & P & Std. \\
\hline FA & $\leftarrow$ & TL & $\mathbf{0 . 1 7 4}$ & $\mathbf{0 . 0 7}$ & $\mathbf{2 . 5 0 6}$ & $\mathbf{0 . 0 1 2} *$ & $\mathbf{0 . 1 9 0}$ \\
FA & $\leftarrow$ & CSE & $\mathbf{0 . 2 5 9}$ & $\mathbf{0 . 0 9 8}$ & $\mathbf{2 . 6 2 9}$ & $\mathbf{0 . 0 0 9 * *}$ & $\mathbf{0 . 2 1 9}$ \\
$\mathrm{TP}$ & $\leftarrow$ & FA & $\mathbf{0 . 1 3 6}$ & $\mathbf{0 . 0 6 4}$ & $\mathbf{2 . 1 3 7}$ & $\mathbf{0 . 0 3 3 *}$ & $\mathbf{0 . 1 6 6}$ \\
$\mathrm{TP}$ & $\leftarrow$ & $\mathrm{TL}$ & 0.029 & 0.054 & 0.528 & 0.597 & 0.038 \\
$\mathrm{TP}$ & $\leftarrow$ & $\mathrm{CSE}$ & 0.018 & 0.077 & 0.232 & 0.817 & 0.018 \\
$\mathrm{CP}$ & $\leftarrow$ & $\mathrm{FA}$ & 0.143 & 0.075 & 1.912 & 0.056 & 0.149 \\
$\mathrm{CP}$ & $\leftarrow$ & $\mathrm{CSE}$ & 0.033 & 0.090 & 0.360 & 0.719 & 0.029 \\
$\mathrm{CP}$ & $\leftarrow$ & $\mathrm{TL}$ & 0.091 & 0.064 & 1.430 & 0.153 & 0.105 \\
\hline
\end{tabular}

Note: Standardized estimating of 10,000 bootstrap sample, $* \mathrm{p}<.05, * * \mathrm{p}<.01$.

\subsection{Mediation Model Analysis}

Mediation effect analysis is also referred to as indirect effect analysis. Previously, to determine whether the mediating effects were valid, several regression models were conducted according to the recommendations of Baron and Kenny (1986). If the total effect of $\mathrm{X}$ to $\mathrm{Y}$ was true and the direct effect of $\mathrm{X}$ to $\mathrm{M}$ (the mediator) was true, the effects of $\mathrm{M}$ and $\mathrm{X}$ on $\mathrm{Y}$ were finally estimated; if $\mathrm{M}$ to $\mathrm{Y}$ was significant, the mediating effect then was considered valid. However, most researchers assert that this 
method is not sufficiently rigorous because the indirect effect is calculated by multiplying the two effects of $\mathrm{X}$ to $\mathrm{M}$ and $\mathrm{M}$ to $\mathrm{Y}$; the fact that these two are true individually does not guarantee that the product is also valid. Therefore, most researchers recommend using the Sobel test (Sobel, 1982, 1986) to test the significance of the aforementioned product. If the Z-value exceeds 1.96, the mediating effect exists; otherwise, it does not exist. Thus, the Sobel test compensates for the insufficiencies of the Baron and Kenny (1986) method instead of replacing it.

MacKinnon (2008) and Hayes (2009) have asserted that the Z-test of the Sobel test assumes that the products of the indirect effect is a normal distribution, however, this assumption is incorrect. Using the value 1.96 for determining significance might cause judgment bias regarding the indirect effect. Therefore, this study employed an asymmetric region bootstrap technique for determining the confidence interval of the indirect effect. In general indirect effect estimation, the standard error of the indirect effect cannot be produced by using general statistical analysis; therefore, calculating confidence intervals (CIs) requires using a bootstrap function through which the standard error is calculated followed by the confidence intervals (MacKinnon, 2008). Mediation is considered supported and the indirect effects statistically significant if the zero is not contained within the confidence interval (Preacher \& Hayes, 2004).

Table 5. Indirect effect analysis for the model

\begin{tabular}{lllll}
\hline \multirow{2}{*}{ Indirect effect } & $\begin{array}{c}\text { Point } \\
\text { estimate }\end{array}$ & \multicolumn{3}{c}{$\begin{array}{c}\text { Bias-corrected CI } \\
\text { bootstrap 1000 times }\end{array}$} \\
\cline { 3 - 5 } & & Lower & Upper & P \\
\hline$H 1 a: \mathrm{TL} \rightarrow \mathrm{FA} \rightarrow \mathrm{TP}$ & 0.024 & 0.002 & 0.061 & 0.023 \\
$H 1 b: \mathrm{TL} \rightarrow \mathrm{FA} \rightarrow \mathrm{CP}$ & 0.025 & 0.003 & 0.079 & 0.047 \\
$H 2 a \mathrm{CSE} \rightarrow \mathrm{FA} \rightarrow \mathrm{TP}$ & 0.035 & 0.003 & 0.109 & 0.024 \\
$H 2 b: \mathrm{CSE} \rightarrow \mathrm{FA} \rightarrow \mathrm{CP}$ & 0.037 & 0.000 & 0.119 & 0.054 \\
\hline
\end{tabular}

Our analysis of results of indirect effect is shown in Table 5. Among the four hypothesized indirect effects of the model, the CIs of first three indirect effects do not contain 0 ; thus the proposed mediating effects of Hypothesis 1a, 1b, and 2a were supported. However, the last indirect effects do contain 0 which indicates that the Hypothesis $2 b$ proposed mediating effect of felt accountability between the relationship of core self-evaluation and contextual performance was not supported.

\section{Discussion}

In practice, proponents posit that the impacts on behavior derived through accountability mechanisms are essential for members' control and thus organizational 
performance (e.g., Frink \& Klimoski, 1998, 2004). However, few case studies have examined individual performance as the expected outcomes through accountability systems (Frinks et al., 2008). Building from current accountability theoretical frames of reference and expectations of management practices, we sought to test the empirical connection of felt accountability with job performance. Moreover, transformational leadership and core self-evaluation are constructs which contain broad implications for the emergence of felt accountability and job performance. Thus the two constructs are introduced into this study to enrich our understanding of the role felt accountability played between the relationships of transformational leadership/core self-evaluation and task performance/contextual performance.

\subsection{Theoretical implications}

What stands out firstly from this study is the confirmation of expectations of management practices that felt accountability is positively related to task performance. Indeed, this finding is consistent with other previous studies linked with accountability theories (e.g., Lerner \& Tetlock, 1994; Frank et al., 2008).

Secondly, with regard to the determinants of felt accountability, leadership and personality traits are the important domains of such determinants. Our results, shown in Table 4, demonstrate a positive relationship of transformational leadership with felt accountability, as well as core self-evaluation and felt accountability.

Thirdly, with respect to the indirect relations, our results, shown in Table 5, demonstrate that felt accountability fully mediates the relationships between transformational leadership and task performance/contextual performance (i.e., Hypothesis 1a, Hypothesis 1b), and core self-evaluation and task performance (i.e., Hypothesis 2a). Whereas, the mediating effect of felt accountability on the relationships between core self-evaluation and contextual performance (i.e., Hypothesis 2b) is not supported.

\subsection{Managerial implications}

We believe that the consistency and potential generalizability of our results on this accountability research have several managerial implications. Firstly, our findings of the direct and positive relationships between accountability and task performance suggest that managers can directly shape their workplace environments in ways that benefit their subordinates to increase their perceptions of accountability, and then to achieve a higher level of job performance. Secondly, our findings of felt accountability mediating the relationships between transformational leadership and 
task/contextual performance, as well as the relationship between core self-evaluation and task performance, suggest that, for the subordinates of transformational leadership or for the subordinates possessing a higher level of core self-evaluation, felt accountability can be thought of as 'catalyst'. This can help ensure that the task objectives assigned to the members of transformational leadership or the subordinates possessing a higher level of core self-evaluation are attained.

\subsection{Limitations and Future Research}

The major purpose of this study was to demonstrate a positive direct and indirect relationships between accountability and job performance in real work settings. The present research has limitations that should be noted. First, we did not control the contextual factors such as industries, firm scale, hierarchical levels, and job characteristics in our survey design. Bass, Avolio, Jung, and Berson (2003) suggest that it may be worthwhile to utilize an experimental design for research under the conditions of high levels of uncertainty, challenge and stress in order to control the research environment. Secondly, we did not introduce moderators in our hypothesized relationships although Lerner and Tetlock (1999) noted that the evidence of accountability depends on a host of moderators and requires a more nuanced assessment (p. 266).

Indeed, offering a more comprehensive test of the target relationship and matching its predictor and criterion of the level of specificity are both necessary approaches in research design. The present study adopted the former approach and focused on the direct and indirect relations of felt accountability to performance behavior. We agree with Barrick, Mount, and Judge's (2001) suggestion that future research on the relationship between perceived accountability and performance behavior at the individual level should consider the potential approaches that link specific, lower-level dimensions or facets of a construct predictor to their relevant specific criterion. Thus, lower level criteria may result in increased correlations and enhance our understanding of the issues. In addition, creating a composite correlation can also result in a more constructive and valid measure of the variable of interest (Higgins, Judge, \& Ferris, 2003). In particular, the perceived accountability has variations that bring about different effects. Although transformational leadership and core self-evaluation are validated multi-dimensional constructs, they can also be rated by various kinds of raters and using subjective or objective different measure tools. In this sense, a future study can be extended, taking mediating effects research on perceived accountability as an example, by linking the five dimensions (idealized attributes, idealized behaviors, inspirational motivation, intellectual stimulation, and 
individualized consideration) separately to performance behaviors as specifically rated by supervisors, peers, customers, or by objective data such as productivity counts, productive or counterproductive behavioral records to test the direct relations. Then, the perceived accountability rated by the employees themselves, supervisors or peers can introduce in-between the above mentioned relationships to test the mediating effects. In short, as Tedd, Steele, and Beauregard (2003) have suggested, the predictors or/and criteria can be considered in more specific terms in any future accountability research.

\section{References}

Anderson, J. C., \& Gerbing, D. W. (1988). Structural equation modeling in practice: A review and recommended two-step approach. Psychological bulletin, 103(3), 411-423.

Aryee, S., Walumbwa, F. O., Zhou, Q., \& Hartnell, C. A. (2012). Transformational leadership, innovative behavior, and task performance: Test of mediation and moderation processes. Human Performance, 25, 1-25.

Bandura, A. (1989). Human agency in social cognitive theory. American Psychologist, 44, $1175-1184$.

Baron, R. M., \& Kenny, D. A. (1986). The moderator-mediator variable distinction in social psychological research: Conceptual, strategic, and statistical considerations. Journal of personality and social psychology, 51(6), 1173-1182.

Barrick, M. R., Mount, M. K., \& Judge, T. A. (2001). Personality and performance at the beginning of the new millennium: What do we know and where do we go next? International Journal of Selection and Assessment, 9, 9-30.

Bartram, T., \& Casimir, G. (2007). The relationship between leadership and follower in-role performance and satisfaction with the leader. Leadership \& Organization Development Journal, 28, 4-19.

Bass, B. M. (1995). Theory of transformational leadership redux. Leadership Quarterly, 6, 463-478.

Bass, B. M., \& Avolio, B. J. (1997). Full range leadership development: Manual for the multifactor leadership questionnaire. CA: Mind Garden.

Bass, B. M., Avolio, B. J., Jung, D. I., \& Berson, Y. (2003). Predicting unit performance by assessing transformational and transactional leadership. Journal of Applied Psychology, $88,207-218$.

Bentler, P. M., \& Wu, E. J. (1993). EQS-Windows user's guide: version 4. BMDP Statistical Software.

Bono, J. E., \& Judge, T. A. (2003). Core self-evaluations: A review of the trait and its role in job satisfaction and job performance. European Journal of Personality, 17, S5-S18 (special issue).

Brown, T. A. (2006). Confirmatory Factor Analysis for Applied Research. New York: Guilford.

Carter, M. Z., Armenakis, A. A., Field, H. S., \& Mossholder, K. W. (2013). Transformational leadership, relationship quality, and employee performance during continuous incremental organizational change. Journal of Organizational Behavior, 34, 942-958.

Chang, C. H., Ferris, D. L., Johnson, R. E., Rosen, C. C., \& Tan, J. A. (2012). Core 
self-evaluations: A review and evaluation of the literature. Journal of Management, 38, $81-128$.

Dvir, T., Eden, D., Avolio, B. J., \& Shamir, B. (2002). Impact of transformational leadership on follower development and performance: A field experiment. The Academy of Management Journal, 45, 735-744.

Elliot, A. J., \& Thrash,T. M. (2002). Approach-avoidance motivation in personality: Approach and avoidance temperaments and goals. Journal of Personality and Social Psychology, 82, 804-818.

Erdogan, B., Sparrowe, R. T., Liden, R. C., \& Dunegan, K. J. (2004). Implications of organizational exchanges for accountability theory. Human Resource Management Review, 14, 19-45.

Erez, A., \& Judge, T.A. (2001). Relationship of core self-evaluations to goal setting, motivation, and performance. Journal of Applied Psychology, 86, 1270-1279.

Ferris, G. R., Dulebohn, J. H., Frink, D. D., George-Falvy, J., Mitchell, T. R., \& Matthews, L. M. (2009). Job and organizational characteristics, accountability, and employee influence. Journal of Managerial Issues, 21(4), 518-533.

Fornell, C., \& Larcker, D. F. (1981). Structural equation models with unobservable variables and measurement error. Journal of marketing research, 18(1), 39-50.

Frink, D. D., \& Ferris, G. R. (1998). Accountability, impression management and goal setting in the performance evaluation process. Human Relations, 51, 1259-1283.

Frink, D. D., Hall, A. T., Perryman, A. A., Ranft, A. L., Hochwarter, W. A., Ferris, G. R., \& Royle, M. T. (2008). Meso-level theory of accountability in organizations. In J.J. Martocchio (Ed.), Research in Personnel and Human Resources Management, Vol. 27 (pp. 177-245). Bingley, UK: Emerald Group Publishing Limited.

Frink, D. D., \& Klimoski, R. J. (1998). Toward a theory of accountability in organizations and human resources management. In G. R. Ferris (Ed.), Research in Personnel and Human Resources Management, Vol. 16 (pp. 1-51). Stamford, CT: JAI Press.

Frink, D. D., \& Klimoski, R. J. (2004). Advancing accountability theory and practice: Introduction to the human resource management review special edition. Human Resource Management Review, 14, 1-17.

Hair, J. F., Black, W. C., Babin, B. J., \& Anderson, E. W. (2009). Multivariate Data Analysis, $7^{\text {th }}$ edition. Englewood Cliffs, N.J. Prentice Hall.

Hall, A. T., Bowen, M. G., Ferris, G. R., Royle, M. T., \& Fitzgibbons, D. E. (2007). The accountability lens: A new way to view management issues. Business Horizons, 50, 405413.

Hall, A. T., \& Ferris, G. R. (2010). Accountability and extra-role behavior. Employ Response Rights Journal. DOI 10.1007/s10672-010-9148-9

Hall, A. T., Frink, D. D., Ferris, G. R., Hochwarter, W. A., Kacmar, C. J., \& Bowen, M. G. (2003). Accountability in human resources management. In C. A. Schriesheim \& L. L. Neider (Eds.), New Directions in Human Resource Management (pp. 29-63). Greenwich, CT: Information Age Publishing.

Hayes, A. F. (2009). Beyond Baron and Kenny: Statistical mediation analysis in the new millennium. Communication Monographs, 76(4), 408-420.

Higgins, C. A., Judge, T. A., Ferris, G. R. (2003). Influence tactics and work outcomes: A meta-analysis. Journal of Organizational Behavior, 24, 89-106.

Hochwarter, W. A., Ferris, G. R., Gavin, M. B., Perrewé, P. L., Hall, A. T., \& Frink, D. D. (2007). Political skill as neutralizer of felt accountability-job tension effects on job performance ratings: A longitudinal investigation. Organizational Behavior and Human 
Decision Processes, 102, 226-239.

Hochwarter, W. A., Perrewé, P. L., Hall, A. T., \& Ferris, G. R. (2005). Negative affectivity as a moderator of the form and magnitude of the relationship between felt accountability and job tension. Journal of Organizational Behavior, 26, 517-534.

Hooper, D., Coughlan, J., \& Mullen, M. (2008). Structural equation modelling: Guidelines for determining model fit. Electronic Journal of Business Research Methods, 6(1), 53-60.

Jackson, D. L., Gillaspy Jr, J. A., \& Purc-Stephenson, R. (2009). Reporting practices in confirmatory factor analysis: an overview and some recommendations. Psychological methods, 14(1), 6-23.

Jöreskog, K. G., \& Sörbom, D. (1989). LISREL 7: A guide to the program and applications (Vol. 2). Chicago: Spss.

Judge, T. A., \& Bono, J. E. (2001). Relationship of core self-evaluation traits-self-esteem, generalized self-efficacy, locus of control, and emotional stability - with job satisfaction and job performance: A meta-analysis. Journal of Applied Psychology, 86, 80-92.

Judge, T. A., Erez, A., Bono, J. E., \& Thoresen, C. J. (2003). The core self-evaluations scale: Development of a measure. Personnel Psychology, 56, 303-331.

Judge, T. A., Locke, E. A., Durham, C. C. (1997). The dispositional causes of job satisfaction: A core evaluations approach. Research in Organizational Behavior, 19, 151-188.

Judge, T. A., \& Kammeyer-Mueller, J. D. (2012). General and specific measures in organizational behavior research: Considerations, examples, and recommendations for researchers. Journal of Organizational Behavior, 33, 161-174.

Kammeyer-Mueller, J. D., Judge, T. A., \& Scott, B. A. (2009). The role of core self-evaluations in the coping process. Journal of Applied Psychology, 94(1), 177-195.

Kenny, D. A. (1979). Correlation and causality. New York: Wiley, 1979, 1.

Kenny, D. A. (2006). Series editor's note. In T. A. Brown (Ed.), Confirmatory Factor Analysis for Applied Research (pp. ix-x). New York: Guilford.

Khanin, D. (2007). Contrasting Burns and Bass: Does the transactional-transformational paradigm live up to Burns' philosophy of transforming leadership? Journal of Leadership Studies, 1, 7-28.

Kline, R. B. (2011). Principles and practice of structural equation modeling. Guilford press.

MacKinnon, D. P. (2008). Introduction to Statistical Mediation Analysis. Routledge.

MacKinnon, D. P., Lockwood, C. M., Hoffman, J. M., West, S. G., \& Sheets, V. (2002). A comparison of methods to test mediation and other intervening variable effects. Psychological Methods, 7, 83-104.

Mero, N. P., Guidice, R. M., \& Anna, A. L. (2006). The interacting effects of accountability and individual differences on rater response to a performance-rating task. Journal of Applied Social Psychology, 36, 795-819.

Lerner, J. S., \& Tetlock, P. E. (1994). Accountability and social cognition. Encyclopedia of Human Behavior, 1, 1-10.

Lerner, J. S., \& Tetlock, P. E. (1999). Accounting for the effects of accountability. Psychological Bulletin, 125, 255-275.

Lerner, J. S., \& Tetlock, P. E. (2003). Bridging individual, interpersonal, and institutional approaches to judgment and choice: The impact of accountability on cognitive bias. In S. Schneider \& J. Shanteau (Eds.), Emerging Perspectives in Judgment and Decision Making (pp. 431-453). Cambridge: Cambridge University Press.

Laird, M. D., Perryman, A. A., Hochwarter, W. A., Ferris, G. R., \& Zinko, R. (2009). The moderating effects of personal reputation on accountability-strain relationships. 
Journal of Occupational Health Psychology, 14, 70-83.

Motowidlo, S. J., \& Van Scotter, J. R. (1994). Evidence that task performance should be distinguished from contextual performance. Journal of Applied Psychology, 79, 475480.

Ones, D. S., Dilchert, S., Viswesvaran, C., \& Judge, T. A. (2007). In support of personality assessment in organizational settings. Personnel Psychology, 60, 995-1027.

Preacher, K. J., \& Hayes, A. F. (2008). Asymptotic and resampling strategies for assessing and comparing indirect effects in multiple mediator models. Behavior research methods, 40(3), 879-891.

Royle, M. T., Hall, A. T., Hochwarter, W. A., Perrewé, P. L., \& Ferris, G. R. (2005). The interactive effects of accountability and job self-efficacy on organizational citizenship behavior and political behavior. Organizational Analysis, 13(1), 53-71.

Schillemans, T. (2010). Redundant accountability: The joint impact of horizontal and vertical accountability on autonomous agencies. Public Administration Quarterly, 34, 300-337.

Sobel, M. E. (1982). Asymptotic confidence intervals for indirect effects in structural equation models. In S. Leinhart (Ed.), Sociological Methodology 1982 (pp. 290-312). San Francisco: Jossey-Bass.

Sobel, M. E. (1986). Some new results on indirect effects and their standard errors in covariance structure models. Sociological methodology, 16, 159-186.

Tedd, R. P., Steele, J. R., \& Beauregard, R. S. (2003). Broad and narrow measures on both sides of the personality-job performance relations. Journal of Organizational Behavior, 24, 335-356.

Tetlock, P. E. (1985). Accountability: The neglected social context of judgment and choice. Research in Organizational Behavior, 7, 297-332.

Tetlock, P. E. (1992). The Impact of accountability on judgment and choice: Toward a social contingency model. Advances in Experimental Social Psychology, 25, 331-376.

Thompson, B. (2004). Exploratory and Confirmatory Factor Analysis: Understanding Concepts and Applications. Washington, DC: American Psychological Association.

Wang, G., Oh, I. S., Courtright, S. H., \& Colbert, A. E. (2011). Transformational leadership and performance across criteria and levels: A meta-analytic review of 25 years of research. Group \& Organization Management, 36, 223-270.

Wang, H., Law, K. S., Hackett, R. D., Wang, D., \& Chen, Z. X. (2005). Leader-member exchange as a mediator of the relationship between transformational leadership and followers' performance and organizational citizenship behavior. The Academy of Management Journal, 48, 420-432.

Williams, L., \& Anderson, S. (1991). Job satisfaction and organizational commitment as predictors of organizational citizenship and in-role behaviors. Journal of Management, 17, 601-617.

Wood, R., \& Bandura, A. (1989). Social cognitive theory of organizational management. The Academy of Management, 14, 361-384. 